\title{
ETOS KERJA DAN TINGKAT KESEJAHTERAAN PETANI DI KABUPATEN BOALEMO
}

\author{
Echan Adam *1), Tity Iriani Datau ${ }^{2)}$ \\ 1) Fakultas Pertanian Universitas Negeri Gorontalo \\ 2) Badan Perencanaan Pembangunan Daerah Provinsi Gorontalo \\ ${ }^{*}$ Penulis Korespondensi, E-mail: echanadam@ung.ac.id
}

\begin{abstract}
ABSTRAK
Penelitian ini bertujuan untuk menganalisis perbandingan tingkat kesejahteraan tipologi masyarakat petani, serta dampak etos kerja terhadap tingkat kesejahteraan rumah tangga petani. Populasi penelitian adalah sebanyak 1.022 petani yakni petani yang menempati kawasan pertanian terpadu di Kabupaten Boalemo. Penentuan sampel menggunakan tehnik stratified sampling dengan rumus Krejcie and Morgan, sehingga diperoleh jumlah sampel sebanyak 88 petani dan kemudian sampel dipilih secara disproportional dan dapat mewakili masing-masing tipologi masyarakat petani. Analisis data dilakukan berdasarkan hasil kuesioner dan wawancara menggunakan tehnik analisis statistik inferensial one way ANOVA welch, serta matriks analisis tingkat etos kerja petani. Hasil penelitian menunjukkan bahwa secara statistik, tingkat kesejahteraan antara tipologi masyarakat PL dengan PNL dan PL dengan PC berbeda secara signifikan dengan rerata perbedaan berada diatas $50 \%$, sedangkan antara PNL dengan PC tidak terdapat perbedaan yang signifikan dengan rerata perbedaan sebesar $19 \%$. Matriks analisis tingkat etos kerja menunjukkan etos kerja petani di Kabupaten Boalemo adalah cukup tinggi (sedang) dengan tingkat rata-rata nilai berada di atas $50 \%$.
\end{abstract}

Kata kunci: Etos kerja; Tipologi Petani; Petani Non-Lokal; Petani Campuran; Kecamatan Wonosari

\section{PENDAHULUAN}

Kesejahteraan masyarakat terus menjadi kata kunci dari upaya pemerintah dalam pengentasan kemiskinan maupun ketimpangan antar daerah. Angka kemiskinan di Indonesia dapat dikatakan masih relatif cukup tinggi dimana sebagian besar didominasi masyarakat petani. Perbandingan antara wilayah perkotaan dengan perdesaan, bahwa angka kemiskinan di perdesaan masih lebih tinggi dimana selisihnya mencapai 6,04\% (BPS, 2019). Ironinya, sektor pertanian masih diakui berperan penting dalam pembangunan nasional terbukti dari kontribusinya terhadap pendapatan rumah tangga, penyedia lapangan pekerjaan, penyumbang devisa negara, dan penyediaan pangan bahkan pada saat krisis (Rusastra dan Erwidodo, 1998; Manullang et. al., 2017; Sugiarto, 2005).

Provinsi Gorontalo memiliki kawasan pertanian terpadu sejak tahun 2015 salah satunya berlokasi di Kecamatan Wonosari Kabupaten Boalemo. Penetapan wilayah kecamatan wonosari sebagai kawasan pertanian terpadu tersebut dinilai sudah tepat karena sebagian besar masyarakat yang menetap berprofesi sebagai petani. Program kawasan pertanian terpadu tersebut merpakan suatu upaya dari pemerintah provinsi untuk membantu masyarakat petani dalam meningkatkan kesejahteraan. Hasil penelitian Datau et al. (2019) menunjukkan bahwa program kawasan pertanian terpadu kecamatan wonosari dapat meningkatkan kesejahteraan petani dimana Nilai Tukar Pendapatan 
Rumah Tangga Petani (NTPRP) lebih dari satu (>1). Lebih lanjut Datau et al. (2019) menyatakan rendahnya NTPRP terhadap total konsumsi dibanding nilai NTPRP terhadap total biaya produksi menunjukkan petani relatif lebih memprioritaskan pendapatannya untuk pemenuhan kebutuhan konsumsi. Akan tetapi, dari pengeluaran petani untuk konsumsi, NTPRP dinilai relatif seimbang. Rasio tingkat daya beli masyarakat petani pun menunjukkan nilai lebih dari satu $(>1)$ dengan rata-rata nilai rasio 2,14 sampa dengan 6,70 (Datau et. al., 2019).

Penelitian ini merupakan bentuk adaptasi dari penelitian yang dilakukan Datau et al. (2019). Dalam penelitian ini, analisis perbandingan dilakukan terhadap tipologi masyarakat petani yang terdiri dari PL, PNL, dan PC yang menempati kawasan pertanian terpadu. Menurut (Datau et. al., 2019) ketiga tipologi masyarakat petani tersebut memiliki karakteristik serta budaya berbeda yang kemudian ini diduga dapat membedakan tingkat etos kerja dari masyarakat petani yang berada di kawasan tersebut.

Moniaga et al. (2012); Marias dan Nurhamlin (2019) mengatakan etos kerja memiliki hubungan yang kuat dalam mempengaruhi kesejahteraan petani. Lebih lanjut Iskandar (2002) menyatakan bahwa etos kerja memiliki korelasi positif dengan produktivitas petani, dimana petani yang memiliki produktivitas tinggi pasti memiliki tingkat etos kerja yang tinggi. Membangkitkan kesadaran, memotivasi, dan bersikap inovatif agar etos kerja meningkat merupakan aspek-aspek yang perlu diperhatikan dalam usaha peningkatan produktivitas petani dalam menggarap lahan pertanian. Moniaga et al. (2012) pun mengatakan tingkat etos kerja tinggi yang mencapai $80 \%$ dapat mempengaruhi secara signifikan tingkat produktivitas petani yang menggarap padi sawah.

Penelitian ini bertujuan untuk menganalisis perbandingan tingkat kesejahteraan masyarakat petani. Selain itu, penelitian ini menganalisis bagaimana dampak etos kerja terhadap tingkat kesejahteraan rumah tangga petani di Kabupaten Boalemo.

\section{METODE}

Penelitian ini dilaksanakan di Kecamatan Wonosari Kabupaten Boalemo dengan objek penelitian adalah rumah tangga petani yang terbagi dalam tipologi masyarakat petani lokal $(\mathrm{PL})$, petani non-lokal (PNL), dan petani campuran (PC). Data yang didapatkan berupa data primer yang diperoleh langsung dari responden terpilih yakni rumah tangga petani padi sawah melalui kuisioner yang dibagikan dan wawancara langsung. Data sekunder juga diperoleh dari berbagai sumber tertulis yang mendukung penelitian ini.

Populasi penelitian ini adalah sebanyak 1.022 petani yang mendapatkan manfaat dari program pengembangan kawasan pertanian terpadu di Kecamatan Wonosari Kabupaten Boalemo tahun 2019. Jumlah sampel ditentukan menggunakan tehnik stratified sampling dengan rumus Krejcie dan Morgan, dan diperoleh jumlah sampel sebanyak 88 petani. Selanjutnya sampel dipilih secara disproportional dan dapat mewakili masing-masing tipologi masyarakat petani. Tehnik penentuan sampel menggunakan rumus Krejcie dan Morgan (Setiawan, 2007) :

Dimana:

$$
n=\frac{\chi^{2} \cdot N \cdot P(1-P)}{(N-1) \cdot d^{2}+\chi^{2} \cdot P(1-P)}
$$

$\mathrm{n} \quad=$ Jumlah sampel

$\mathrm{N}=$ Jumlah Populasi

$\chi^{2}=$ Nilai chi kuadrat

$\mathrm{P}=$ Proporsi populasi

$\mathrm{d}=$ Batas toleransi kesalahan $10 \%$

Asumsi keseragaman populasi yang dimasukkan dalam perhitungannya adalah $P(1-P)$, dimana $P=0,5$ 


$$
\begin{aligned}
& \mathrm{n}=\frac{3,841 \times 1022 \times 0,5(1-0,5)}{(1.022-1)(0,1)^{2}+3,841 \times 0,5(1-0,5)} \\
& \mathrm{n}=\frac{981,3755}{10,21+0,96025} \\
& \mathrm{n}=\frac{981,3755}{11,17025} \\
& \mathrm{n}=88
\end{aligned}
$$

Selanjutnya data dianalisis menggunakan tehnik statistik inferensial one way ANOVA welch dengan terlebih dahulu dilakukan uji asumsi normalitas dan homogenitas. Tingkat etos kerja ditentukan dengan matriks analisis tingkat etos kerja petani, dengan interpretasi hasil sebagai berikut:

Tabel 1. Intepretasi Tingkat Etos Kerja Menurut Kriteria

\begin{tabular}{cc}
\hline Tingkat Etos Kerja (\%) & Tingkat Etos Kerja \\
\hline 1 s.d 20 & Sangat Rendah \\
$>20$ s.d 40 & Rendah \\
$>40$ s.d 60 & Sedang \\
$>60$ s.d 80 & Tinggi \\
$>80$ s.d 100 & Sangat Tinggi \\
\hline
\end{tabular}

Sumber: Moniaga, et al., 2012

\section{HASIL DAN PEMBAHASAN}

\section{Profil Demografi Responden}

Usia responden merupakan salah satu ukuran dalam kategori produktif. Usia 41 tahun sampai dengan 50 tahun terlihat lebih mendominasi dalam tipologi masyarakat petani dibanding rentang usia yang lain, sedangkan usia dibawah 30 tahun hampir tidak ada. Dalam beberapa tahun sebagian masyarakat petani berusia 41-50 tahun akan

\begin{tabular}{|c|c|c|c|c|c|}
\hline \multirow{2}{*}{ Uraian } & \multicolumn{3}{|c|}{ Tipologi Masyarakat Petani } & \multirow{2}{*}{ Jumlah } & \multirow{2}{*}{$\%$} \\
\hline & Lokal & Non-Lokal & Campuran & & \\
\hline \multicolumn{6}{|c|}{$\begin{array}{l}\text { Rentang Usia } \\
\text { Petani (Tahun) }\end{array}$} \\
\hline$<30$ & 1 & 0 & 1 & 2 & 2,27 \\
\hline $31-40$ & 8 & 10 & 9 & 27 & 30,68 \\
\hline $41-50$ & 18 & 16 & 11 & 45 & 51,14 \\
\hline$>50$ & 3 & 6 & 5 & 14 & 15,91 \\
\hline \multicolumn{6}{|l|}{ Pendidikan } \\
\hline SD & 14 & 15 & 9 & 38 & 43,18 \\
\hline SMP & 14 & 11 & 10 & 35 & 39,77 \\
\hline SMA & 2 & 5 & 7 & 14 & 15,91 \\
\hline D3 / S1 & 0 & 1 & 0 & 1 & 1,14 \\
\hline \multicolumn{6}{|c|}{$\begin{array}{l}\text { Jumlah Anggota } \\
\text { RT (Orang) }\end{array}$} \\
\hline$<3$ & 4 & 2 & 2 & 8 & 9,09 \\
\hline $3-5$ & 26 & 27 & 24 & 77 & 87,50 \\
\hline$>5$ & 0 & 3 & 0 & 3 & 3,41 \\
\hline
\end{tabular}
memasuki masa tidak produktif lagi, sedangkan petani yang berusia 31-40 tahun harus terus didorong agar supaya tetap produktif.

Tabel 2. Profil Demografi Responden 
Tingkat pendidikan dapat mempengaruhi cara berpikir seseorang dalam mengelola usaha, begitupun dengan responden yang menjalankan usahatani. Responden sebagian kecil yang lulus SMA. Responden yang melanjutkan ke perguruan tinggi hampir tidak ada dan sebagian besar tingkat pendidikan responden hanya sampai pada tingkat SD maupun SMP. Lebih lanjut, setiap petani responden adalah sebagai kepala rumah tangga dan sebagian besar memiliki jumlah anggota rumah tangga 3-5 anggota keluarga. Banyaknya jumlah anggota dalam rumah tangga petani, tentu dapat mempengaruhi tingkat pengeluaran petani yang semakin besar.

\section{Perbandingan Tingkat Kesejahteraan Rumah Tangga Petani Pada Tipologi Masyarakat Petani}

Analisis perbandingan tingkat kesejahteraan rumah tangga petani dilakukan dengan pengujian statistik yaitu analisys of variance (one way anova). Tabel 3 menunjukkan perbandingan perbedaan rata-rata tipologi masyarakat petani, yaitu tingkat kesejahteraan antara PL dengan PNL, PL dengan PC, dan PNL dengan PC. Secara statistik terdapat perbedaan tingat kesejahteraan antara tipologi masyarakat $\mathrm{PL}$ dengan $\mathrm{PNL}$ dengan $p$ value lebih kecil dari alpha $5 \%(0,022<0,05)$. Dari perbedaan rerata terlihat sebesar $59 \%$ rata-rata nilai NTPRP.

Tabel 3 Hasil Analisis Post Hoc Games-Howell

\begin{tabular}{|c|c|c|c|c|c|}
\hline \multirow{2}{*}{$\begin{array}{l}\text { Tipologi } \\
\text { Petani }\end{array}$} & \multirow{2}{*}{$\begin{array}{l}\text { Perbedaan } \\
\text { Rerata }\end{array}$} & \multicolumn{2}{|c|}{ IK95\% } & \multirow{2}{*}{$p$-value } & \multirow{2}{*}{ Keterangan } \\
\hline & & Min. & Max. & & \\
\hline $\begin{array}{l}\text { Lokal (L) vs } \\
\text { Non-Lokal (NL }\end{array}$ & 0,59 & 0,07 & 1,11 & 0,022 & $\begin{array}{c}\text { Ada } \\
\text { Perbedaan }\end{array}$ \\
\hline $\begin{array}{l}\text { Lokal (L) vs } \\
\text { Campuran (C) }\end{array}$ & 0,78 & 0,20 & 1,36 & 0,006 & $\begin{array}{c}\text { Ada } \\
\text { Perbedaan }\end{array}$ \\
\hline $\begin{array}{l}\text { Non-Lokal (NL) } \\
\text { vs Campuran (C) }\end{array}$ & 0,19 & $-0,46$ & 0,83 & 0,760 & $\begin{array}{l}\text { Tidak Ada } \\
\text { Perbedaan }\end{array}$ \\
\hline
\end{tabular}

Sumber: Data diolah, 2020

Selanjutnya, secara statistik terdapat perbedaan tingat kesejahteraan antara tipologi masyarakat $\mathrm{PL}$ dengan $\mathrm{PC}$ dimana $p$-value $0,006<0,05$. Perbedaan rerata menunjukkan presentase sebesar $78 \%$ rata-rata nilai NTPRP. Hasil ini membuktikan ada perbedaan signifikan tingkat kesejahteraan antara PL dengan PC. Akan tetapi, berbeda hasilnya tingkat kesejahteraan antara masyarakat PNL dengan PC, dimana kedua tipologi tersebut secara statistik tidak menunjukkan perbedaan, dimana $p$-value $0,760>0,05$. Dari perbedaan rerata juga membuktikan bahwa antara tipologi masyarakat PNL dengan PC hanya sebesar $19 \%$ rata-rata nilai NTPRP. Dengan demikian, perbedaan tingkat kesejahteraan rumah tangga petani hanya terjadi pada tipologi masyarakat PL dengan PNL, dan antara PL dengan PC.

Tabel 4 menunjukkan nilai signifikasnsi ( $p$-value) dari test of normality faktor dari tipologi masyarakat petani masing-masing berada diatas nilai alpha (a) $5 \%$. Artinya bahwa keputusan data yang digunakan terdistribusi normal, sehingga dapat dilanjutkan untuk pengujian one way anova. Selanjutnya, test of homogenity of variance terbukti bahwa nilai signifikansinya adalah sebesar 0,023 dan lebih kecil dari nilai alpha (a) $5 \%$. Hasil tersebut dapat disimpulkan paling tidak terdapat dua kelompok yang dibandingkan dalam penelitian ini memiliki varian yang berbeda. Hasil uji one way anova welch menunjukkan pula bahwa nilai signifikansinya $(0,002)$ lebih kecil dari nilai alpha (a) $5 \%(0,002<0,005)$. Ini membuktikan bahwa paling tidak terdapat dua kelompok dari tipologi masyarakat petani yang memiliki rata-rata tingkat kesejahteraan yang berbeda bermakna. 
Tabel 4 Hasil Pengujian Asumsi Normalitas dan Homogenitas, dan Analisys of Variance (Anova Welch)

\begin{tabular}{llcc}
\hline & $\begin{array}{l}\text { Tipologi } \\
\text { Petani }\end{array}$ & p-value & Keterangan \\
\hline Test of Normality & Lokal (L) & 0,200 & Normal \\
& Non-Lokal (NL) & 0,200 & Normal \\
& Campuran (C) & 0,200 & Normal \\
$\begin{array}{l}\text { Test of Homogenity } \\
\text { of Variance }\end{array}$ & & 0,023 & Tidak Homogen \\
$\begin{array}{l}\text { Analisys of variance } \\
\text { (Anova Welch) }\end{array}$ & & 0,002 & Signifikan \\
\hline
\end{tabular}

Sumber: Data diolah, 2020

\section{Dampak Etos Kerja Petani Terhadap Tingkat Kesejahteraan Rumah Tangga Petani}

Dalam penelitian ini tingkat kesejahteraan rumah tangga petani dari tipologi masyarakat petani diukur dengan tingkat pendapatan dan pengeluaran petani melalui indikator rasio nilai tukar rumah tangga petani (NTPRP). Rata-rata NTPRP yang dimiliki tipologi masyarakat PL, PNL, dan PC adalah positif (berada diatas angka 1) dan terbukti bahwa rata-rata rumah tangga petani di Kecamatan Wonosari adalah sejahtera (Datau, et al., 2019). Namun, secara statistik ditemukan bahwa tingkat kesejahteraan antara beberapa kelompok petani ada perbedaan yang bermakna, yaitu antara tipologi masyarakat PL dan PNL, dan juga antara tipologi PL dan PC. Faktanya pun ditemukan rata-rata perbedaan rasio NTPRP antara tipologi petani baik PL dengan PNL, maupun PL dengan PC berada diatas $50 \%$.

Iskandar (2002); dan Tasmara (1991) menjelaskan etos kerja yang dimiliki petani dapat memberikan dampak positif terhadap produktivitas petani yang diukur dengan tingkat pendapatan yang diperoleh. Lebih lanjut, Tasmara (1991) menjelaskan bahwa etos kerja yang tinggi berarti petani bersungguh-sungguh bekerja dengan segala potensi yang dimilikinya untuk mencapai tujuan, bekerja efektif, tidak cepat merasa puas dengan hasil yang diperoleh, tidak boros, dan memiliki antusias tinggi dalam bekerja. Iskandar (2002) menemukan bahwa 34\% variabel etos kerja dapat mempengaruhi peningkatan produktivitas petani. Hasil penelitian Alpian et al. (2016); Moniaga et al. (2012) juga mendukung dengan menyatakan hubungan yang kuat dan bermakna antara etos kerja dengan produktivitas petani padi sawah hingga 67\%. Etos kerja yang berwujud menjadi suatu perilaku kerja yang positif petani telah memberi efek terhadap tingkat kesejahteraan pada tipologi masyarakat petani di Kecamatan Wonosari.

Tabel 5 menunjukkan tingkat etos kerja petani dari ketiga tipologi masyarakat petani adalah bervariasi. Para petani yang bekerja sebagai petani padi sawah di Kecamatan Wonosari dapat dikatakan telah berpengalaman dalam berusaha tani. Ratarata lama bekerja dari tipologi masyarakat petani tersebut berada di atas sepuluh tahun (> 10 tahun), bahkan untuk petani non-lokal rata-rata berada di atas dua puluh tahun $(>20$ tahun). Artinya, petani telah mapan dalam mengelola usahatani khususnya sebagai petani padi sawah. Dari hasil wawancara dengan petani, 53\% - 62\% petani tersebut dibantu oleh keluarganya dalam mengelola usaha, dengan bekerja rata-rata 5-7 jam setiap harinya. Kesungguhan para petani dalam bekerja dengan seluruh potensi yang dimiliki untuk mencapai sesuatu, dan juga sangat menghargai waktu adalah indikasi bahwa petani bekerja keras dan memiliki tanggung jawab yang tinggi. Kerja keras dan bertanggung jawab dapat memberikan hasil yang terbaik. Terbukti bahwa rata-rata pendapatan melalui indikator NTPRP petani berada di atas rata-rata nilai, dan mengindikasikan bahwa petani relatif sejahtera.

Dalam mengelola usahatani pun, petani sangat memperhatikan efektifitas dan efisiensi biaya. Pengeluaran untuk pembiayaan usaha dapat ditekan dengan 
pemanfaatan teknologi pertanian yang semakin canggih. Lebih dari $60 \%-70 \%$ petani baik dari tipologi masyarakat PL, PNL, dan PC telah menggunakan peralatan modern dibanding menggunakan peralatan tradisional. Hal lain yang mendukung adalah dengan keterlibatan petani dalam pelatihan-pelatihan (40\% - 50\%) yang dapat menunjang kinerja petani seperti: mengikuti penyuluhan pertanian, pelatihan pemilihan benih unggul, pelatihan pembuatan pupuk, pembangunan drainase, maupun hal-hal yang berkaitan dengan pengenalan kelembagaan agribisnis yang dapat menunjang usaha-usaha atau bisnis pertanian.

Dari sisi permasalahan dalam mengelola usahatani sampai pada pemenuhan kebutuhan rumah tangga petani, seperti masalah permodalan dan harga, dari tipologi masyarakat petani tersebut $50 \%$ - 69\% dapat mengatasinya dengan baik, meskipun ada juga petani yang mengeluh karena belum dapat mengatasinya, terutama dalam hal akses ke permodalan. Permasalahan-permasalahan tersebut sudah sering terjadi dan tentu tidak mempengaruhi etos kerja petani. Secara keseluruhan, nilai etos kerja dari ketiga tipologi masyarakat petani rata-rata berada di atas 50\%. Artinya bahwa etos kerja yang dimiliki kelompok petani baik dari PL, PNL, dan PC cukup tinggi.

Tabel 5 Matriks Analisis Etos Kerja Tipologi Masyarakat Petani

\begin{tabular}{|c|c|c|c|c|c|c|c|}
\hline \multirow{3}{*}{ No } & \multirow{3}{*}{ Uraian } & \multicolumn{6}{|c|}{ Tipologi Petani } \\
\hline & & \multicolumn{2}{|c|}{$\begin{array}{l}\text { Lokal } \\
(\mathrm{L})\end{array}$} & \multicolumn{2}{|c|}{$\begin{array}{l}\text { Non- Lokal } \\
\text { (NL) }\end{array}$} & \multicolumn{2}{|c|}{$\begin{array}{l}\text { Campuran } \\
\text { (C) }\end{array}$} \\
\hline & & $\begin{array}{l}\text { Rata- } \\
\text { Rata }\end{array}$ & $\%$ & $\begin{array}{l}\text { Rata- } \\
\text { Rata }\end{array}$ & $\%$ & $\begin{array}{l}\text { Rata- } \\
\text { Rata }\end{array}$ & $\%$ \\
\hline 1. & Lama bekerja (tahun) & 14,73 & 43,3 & 20,09 & 46,9 & 16,38 & 42,3 \\
\hline 2. & $\begin{array}{l}\text { Memilih mengelola } \\
\text { usahatani bersama } \\
\text { keluarga }\end{array}$ & 1,53 & 53,3 & 1,59 & 59,4 & 1,62 & 61,5 \\
\hline 3. & $\begin{array}{l}\text { Jam kerja usahatani padi } \\
\text { sawah dalam sehari }\end{array}$ & 6,5 & 56,7 & 5,97 & 50,0 & 6,35 & 53,8 \\
\hline 4. & $\begin{array}{l}\text { Memilih mengelola secara } \\
\text { modern }\end{array}$ & 1,7 & 63,3 & 1,81 & 78,1 & 1,77 & 76,9 \\
\hline 5. & $\begin{array}{l}\text { Jam kerja non usahatani } \\
\text { dalam sehari }\end{array}$ & 2,9 & 56,7 & 3,34 & 46,9 & 3,46 & 53,8 \\
\hline 6. & Pernah mengikuti pelatihan & 0,4 & 40,0 & 0,50 & 50,0 & 0,42 & 42,3 \\
\hline 7. & $\begin{array}{l}\text { Adanya Kebiasaan gotong } \\
\text { royong sesama anggota }\end{array}$ & 0,5 & 53,3 & 0,50 & 50,0 & 0,31 & 30,8 \\
\hline \multirow[t]{2}{*}{8.} & $\begin{array}{l}\text { Tdak ada kendala dalam } \\
\text { usahatani/rumah tangga } \\
\text { petani }\end{array}$ & 0,7 & 33,3 & 0,53 & 50,0 & 0,69 & 30,8 \\
\hline & Rata-Rata & & 50,0 & & 53,9 & & 52,8 \\
\hline
\end{tabular}

Sumber: Data primer diolah, 2020

Menurut Morgan (1961); Moniaga et al., (2012) mengatakan ada banyak cara yang dapat dilakukan dalam tujuan untuk pengembangan dan peningkatan etos kerja. Etos kerja menjadi dasar dari sikap terhadap diri, serta merupakan aspek evaluatif yang bersifat menilai membangkitkan kesadaran agar etos kerja petani meningkat. Meningkatnya etos kerja petani akan meningkatkan pendapatannya dan mensejahterakan kehidupan petani. Sisi lain, Sukirno (2010) mengatakan bahwa kebudayaan atau adat istiadat merupakan faktor non-ekonomi yang juga dapat berpengaruh pada pola perilaku dalam berusaha sehingga mempengaruhi produktivitas dan pendapatan.

Tipologi PNL dan PC yang sebagian besar berasal dari luar suku gorontalo yang diketahui berasal dari Jawa, Bali, dan Lombok. Tipologi PNL dan PC tersebut memiliki perilaku berbeda dengan tipologi PL. Dalam kegiatan keseharian sangat sedikit PNL maupun PC ditemukan siang hari berada di rumah, kebanyakan dari mereka mulai 
bekerja selepas waktu shubuh untuk pergi ke ladang dan kembali ke rumah pada waktu sore hari (menjelang waktu magrib). Ini berbeda dengan tipologi PL dimana sebagian besar mereka berangkat kerja jam tujuh pagi (pukul 7.00 a.m) dan selesai sebelum jam empat sore (pukul 15.30 p.m). Kenyataan tersebut mengindikasikan perbedaan tingkat etos kerja antara tipologi PL dengan PNL, antara PL dengan PC dari sisi kerja keras, tanggung jawab, dan kemandirian berusahatani sehingga berdampak pada perbedaan tingkat kesejahteraan.

\section{SIMPULAN}

Perbandingan tingkat kesejahteraan antara PL dengan PNL dan antara PL dengan PC secara statistik masing-masing terdapat perbedaan tingat kesejahteraan dengan nilai $p$-value masing-masing 0,022 dan 0,006. Perbedaan rerata pendapatan antara PL dengan PNL dan PL dengan PC adalah bermakna. Perbedaan antara tipologi masyarakat PL dengan PNL dan juga antara PL dan PC berada antara 59\% sampai pada $78 \%$ ratarata nilai NTPRP.

Etos kerja petani dari tipologi masyarakat petani adalah dinilai cukup tinggi dan berpengaruh terhadap tingkat kesejahteraan. Tingkat etos kerja ketiga tipologi masyarakat petani rata-rata berada diatas $50 \%$. Tingkat etos kerja memberikan dampak yang baik terhadap tingkat kesejahteraan petani lokal (PL), petani non-lokal (PNL), dan petani campuran (PC).

\section{DAFTAR PUSTAKA}

Alpian, Mulatsih Sri L., Djohar D. (2016). Pengaruh Etos Kerja, Motivasi Dan Sikap Inovatif Terhadap Produktivitas Peternak Pembibitan Sapi Potong Di Kabupaten Pasaman Barat. Artikel Universitas Bung Hatta. Padang http://ejurnal.bunghatta.ac.id/index.php?journal=JPSC2\&page=article\&op=viewFile \&path[] $=7726$ \&path[] $=6537$

Badan Pusat Statistik. (2019). Profil Kemiskinan di Indonesia. Berita Resmi Statistik, 56, 1-12. https://www.bps.go.id/pressrelease/2020/01/15/1743/persentase-pendudukmiskin-september-2019-turun-menjadi-9-22-persen.html

Datau, T. I., Canon, S., \& Halid, A. (2019). Tingkat Kesejahteraan Rumah Tangga Petani Menurut Tipologi Masyarakat. Jambura Agribusiness Journal, 1(1), 26-35. http://dx.doi.org/10.37046/jaj.v1i1.2447

Iskandar, O. (2002). Etos Kerja, Motivasi, Dan Sikap Inovatif Terhadap Produktivitas Petani. Makara Human Behavior Studies in Asia, 6(1), 26. https://doi.org/10.7454/mssh.v6i1.28

Manullang Elfrida N., Noor Insan T., Pardian P., dan Syamsiyah Nur. (2017). Analisis Pendapatan Dan Tingkat Kesejahteraan Rumah Tangga Petani Kedelai Di Kecamatan Jatiwaras, Kabupaten Tasikmalaya, Provinsi Jawa Barat. AGROINFO GALUH, 4(3), 464-471 http://dx.doi.org/10.25157/jimag.v4i3.1650

Marias, P., dan Nurhamlin. (2019). Hubungan Etos Kerja Terhadap Kesejahteraan Petani Karet Di Desa Pulau Pulau Mungkur Kecamatan Gunung Toar Kabupaten Kuantan Singingi. JOM FISIP, 6(1), 1-13

Moniaga, Vicky R.B., Jelly M., dan Christy Rondonuwu. (2012). Hubungan Antara Etos Kerja, Motivasi, Sikap Inovatif Dan Produktivitas Usahatani (Studi Kasus Pada Usahatani Padi Sawah Di Kecamatan Tumpaan Kabupaten Minahasa Selatan). Jurnal ASE, 8(1), 45-57 https://doi.org/10.35791/agrsosek.8.1.2012.7360

Morgan, T. Clifford. (1961). Introduction to Psychology. New York: Mc Graw Hill Book Company Inc. 
Rusastra, I. W., \& Erwidodo, N. (2016). Growth, Equity and Environmental Aspects of Agricultural Development in Indonesia. Forum Penelitian Agro Ekonomi, 16(1), 3261. https://doi.org/10.21082/fae.v16n1.1998.32-41

Setiawan, N. (2017). Penentuan Ukuran Sampel Memakai Rumus Slovin dan Tabel Krejcie-Morgan: Telaah Konsep dan Aplikasinya. Diskusi IImiah Jurusan Sosial Ekonomi Fakultas Peternakan UNPAD, November, 10. http://pustaka.unpad.ac.id/wpcontent/uploads/2009/03/penentuan_ukuran_sampel_memakai_rumus_slovin.pdf

Sugiarto. (2009). Analysis of Farmer's Welfare Level by Pattern of Income and Expenditure in Rural Areas. Pusat Analisis Sosial Ekonomi Dan Kebijakan Pertanian, 1, 248-260.

Sukirno, Sadono. (2010). Ekonomi Pembangunan. Edisi kedua. Jakarta: Kencana Prenada Media Group

Tasmara, Toto. (1991). Etos Kerja Pribadi Muslim. Jakarta: Labmen 